\title{
Intellectual humility in mathematics
}

\section{Colin Jakob Rittberg ${ }^{1}$}

Received: 11 May 2020 / Accepted: 16 January 2021 / Published online: 11 February 2021

(c) The Author(s) 2021

\begin{abstract}
In this paper I explore how intellectual humility manifests in mathematical practices. To do this I employ accounts of this virtue as developed by virtue epistemologists in three case studies of mathematical activity. As a contribution to a Topical Collection on virtue theory of mathematical practices this paper explores in how far existing virtue-theoretic frameworks can be applied to a philosophical analysis of mathematical practices. I argue that the individual accounts of intellectual humility are successful at tracking some manifestations of this virtue in mathematical practices and fail to track others. There are two upshots to this. First, the accounts of the intellectual virtues provided by virtue epistemologists are insightful for the development of a virtue theory of mathematical practices but require adjustments in some cases. Second, the case studies reveal dimensions of intellectual humility virtue epistemologists have thus far overlooked in their theoretical reflections.
\end{abstract}

Keywords Humility · Philosophy of mathematical practices · Virtue epistemology · Virtue $\cdot$ Erdős-Selberg dispute $\cdot$ Abc-conjecture $\cdot$ Multiverse logic

\section{Introduction}

To understand an intellectual virtue is to understand how it may manifest in an epistemic situation. Virtue epistemologists describe these epistemic situations using thought experiments or draw on works of literature, such as Roberts and Wood's (2007) use of works by Jane Austen. The situations discussed are typically everyday situations, such as admitting to one's intellectual limitations in front of people one wishes to impress (Whitcomb et al. 2017). Epistemic situations that arise in the context of actual intellectual practices are usually not discussed. ${ }^{1}$ I argue that this is an oversight. Carrying out an epistemic activity in the context of an intellectual practice

\footnotetext{
1 Noteworthy exceptions can be found in Kidd et al. (2017), van Dongen and Paul (2017), and the contributions to this Topical Collection (Aberdein et al. 2020).

Colin Jakob Rittberg

jakob.rittberg@gmail.com

1 Logic and Philosophy of the Cognitive Sciences, Vrije Universiteit Amsterdam, Amsterdam, The Netherlands
} 
means to be subject to the epistemic norms, values, and goals of that practice. Virtue ethicist Alistair MacIntryre (1981) has argued that for a practitioner to act virtuously is to act in a way that is conducive to the aims of the practice in the context of human life. In such a framework, any successful account of an intellectual virtue has to be deeply connected to the intellectual practice under consideration. As an example, consider open-mindedness, i.e. the willingness to change one's beliefs, in mathematical proving practices. According to Dutilh Novaes' (2016) Prover-Skeptic model, a mathematical proof is a dialogical argument in which Prover tries to convince Skeptic of the correctness of her proof. The epistemic norms of mathematical proving practices demand that Skeptic be stubbornly doubtful in a way in which ordinary arguers are not. Virtuous manifestation of open-mindedness may thus manifest differently for mathematicians in their role as Skeptic compared to ordinary arguers. To develop a virtue theory of an intellectual practice may hence require adjusting the general accounts of the virtues as provided by virtue epistemology to the specifics of the intellectual practice in question.

In their contribution to this Topical Collection, Tanswell and Kidd (2020) take seriously the insight that virtues may vary across and within different disciplines and projects and explore it in detail. They ask whether the virtues of a practice are better understood as generic virtues, pertinent to all forms of epistemic activity in a domain neutral way, that take on forms specific to that practice, or whether practices are better understood in terms of local virtues; e.g. is mathematical rigour a specific form of the general virtues of meticulousness and carefulness, or is mathematical rigor an excellence that can only properly be exercised in a mathematical practice and hence a local virtue ${ }^{2}$ In this paper I explore the former for intellectual humility. I investigate how well accounts of intellectual humility as a generic epistemic virtue trace specific instances of (failed) manifestations of the virtue in mathematical practices.

Intellectual humility has attracted considerable attention by virtue epistemologists in recent years (Whitcomb et al. 2017; Kidd 2016; Tanesini 2018; Hazlett 2012; Spiegel 2012; Roberts and Wood 2007; Driver 1989). In this paper I explore how apt the accounts of the virtue epistemologists of intellectual humility as a generic virtue (in the sense of Tanswell and Kidd) are at tracking (failed) manifestations of the virtue in mathematical practices by employing them in three case studies. I focus on three such accounts of the virtue by Roberts and Wood, Whitcomb et al., and Kidd. I will argue that these accounts of intellectual humility as a generic virtue are each successful at tracking some manifestations of the virtue but fail to track others. This has two upshots. First, philosophers of mathematics learn that the theoretical framework of the virtues as provided by virtue epistemologists benefits from adjustment to the case of mathematics. Second, virtue epistemologists find their reflections employed in concrete case studies which partially challenge their accounts.

As an indication of these upshots, consider the narrative that mathematics ensures humility because mathematicians have to submit to the force of mathematical reasoning (see Sect. 2). From virtue theory we can learn that virtues are too soft to

\footnotetext{
${ }^{2}$ For a virtue-theoretic analysis of mathematical rigour, see Tanswell (2016).
} 
be brought about by any tool-like machinery. The mere following of mathematical deductive rules thus cannot ensure virtuous mathematical activity. In this paper I explore dimensions of intellectual humility besides such rule-following. Part of these is that intellectual humility can manifest in intellectual dispute. As I will show (esp. Sect. 4), disagreeing parties can charge each other with a lack of humility. This becomes clearly visible when studying real-life cases but has remained hidden in the thought-experiment driven analysis favoured by much of contemporary virtue epistemology.

Here is an overview of this paper. In Sect. 2 I introduce intellectual humility. This virtue is the epistemic version of the moral virtue "humility". I remark on the historicity of humility and suggest that old conceptions of the virtue influence how some mathematicians conceive of humility in mathematics. I then move to a discussion of intellectual humility in which I present three accounts of the virtue (Whitcomb et al. 2017; Kidd 2016; Roberts and Wood 2007), which I will employ in my case studies in the following sections.

In Sect. 3 I discuss the dispute between Atle Selberg and Paul Erdős about the authorship of the elementary proof of the Prime Number Theorem. The case shows that the pursuit of intellectual humility cuts across MacIntyre's distinction of internal and external goods of a practice. As I will show, this provides a line of defence for Roberts and Wood (2007) against criticisms raised by Whitcomb et al. (2017).

In Sect. 4 I focus more explicitly on the epistemic dimension of the virtue by discussing proof appraisal in mathematics. I present Mochizuki's proposed proof of the abc-conjecture as a case in which mathematicians disagree about the mathematical correctness of a proof. I explore how in the abc-conjecture case humility (fails to) manifests in proof presentation and the judgment of who counts as a relevant expert. Current accounts of intellectual humility will prove largely inapt at tracking intellectual humility in the abc-conjecture case.

In Sect. 5 I present Väänänen's recent development of so-called multiverse logic to show how intellectual humility may manifest when deeply held assumptions of a mathematical practice become disputed. I argue against a conception of intellectual humility as a submission to one's intellectual practice and propose that Väänänen manifests intellectual humility when he appropriates assumptions of set-theoretic practice for the development of his formal framework.

In my conclusion in Sect. $6 \mathrm{I}$ argue for the two principal claims of this paper. First, virtue theorists of mathematics stand to benefit from appropriating accounts of the intellectual virtues provided by the virtue epistemologists. Second, virtue epistemology is enriched through analyses of the virtues in the context of real life practices.

\section{Intellectual humility}

In this section I introduce accounts of intellectual humility. Intellectual humility is the epistemic version of the moral virtue humility. This moral virtue has a rich history. In this section I touch upon this history to suggest that what I will call, with Rushing (2013), the Christian conception of humility influences how some 
mathematicians think about humility in the context of their epistemic practice. The Christian conception of the virtue, and in particular the criticisms it has received, also influence the contemporary debate about intellectual humility. I draw on these to introduce three accounts of intellectual humility which shape the current debate in virtue epistemology about the virtue and which I will employ in the case studies in the following sections; (Roberts and Wood 2007; Kidd 2016; Whitcomb et al. 2017).

\subsection{Humility}

Aristotle mentions humility in II.7 of the Nicomachean Ethics, where he presents the virtues as means between two vices. "Proper pride" is a virtue situated between the excess "empty vanity" and the deficiency of "undue humility" (Brown 2009). ${ }^{3}$ Aristotle elaborates in IV.3: "The man who thinks himself worthy of less than he is really worthy of is unduly humble, whether his deserts be great or moderate, or his deserts be small but his claims yet smaller". These discussions of undue humility raise the question what a proper kind of humility may be. Aristotle provides no clear answer. Later in IV.3 (1125b) he seems to suggest that the humble are those who are unable to provide aide. Proper humility may thus be a correct assessment of one's inabilities. 4

For Aristotle, proper pride is a virtue and humility, in as far as it is a virtue at all, is only a minor virtue. In what Rushing (2013) called the "Christian conception of humility", this is reversed. ${ }^{5}$ Konkola (2005) helpfully reminds us that according to Christian scripture, Lucifer rebelled against God out of pride. Humility is a Christian means to guard against pride, i.e. unlike Aristotle, for whom (proper) pride was a virtue, pride is a vice in Christian thinking. In his Psychomachia, in which personifications of the seven heavenly virtues battle the seven deadly sins in a fight for mans' soul, the Roman Christian Poet Prudentius rendered the opposition between humility and pride as a fight between the (Christian) virtue and the (Christian) vice. Pride bellows insults and charges at Humility on her chariot. Prior to the battle the minor vice Deceit has dug a ditch for Humility's army to fall into, but Humility, in her meekness, has not even advanced far enough to reach the trap. It is Pride in her charge who falls into the trap and Humility quickly decapitates her and thus wins her part of the battle for man's soul.

Prudentius' rendering glorifies a conception of humility as what Konkola called a "cultivated meekness". Rushing (2013) uses the terms "lowliness", "self-debasement", "self-abnegation", "obedience", and "submission to authority" to describe the Christian conception of humility. The authority submitted to, the other to

\footnotetext{
${ }^{3}$ Sachs (2002) translates as "greatness of soul" instead of proper pride and "smallness of soul" instead of humility.

${ }^{4}$ This aligns with Whitcomb et al. (2017) introduced below. Whitcomb et al. do not draw the connection between their account and Aristotle's.

${ }^{5}$ Rushing's (2013) interest is in what humility in Confucianism may amount to. Due to lack of space I will not engage with this conception of the virtue.
} 
which one's own relative lowliness is professed, and to whom the Christian is obedient is, of course, the Christian God. The humble Christian who accepts his lowliness before this God could never rebel against the Lord as Lucifer did. Humility is thus a means to guard against pride. Konkola (2005) explores some of the extreme forms this could take. Witness, for example, Thomas A. Kempis' Of the Imitation of Christ, cited in (Konkola 2005, p. 184):

Learn to obey, you dust; learn to bring down yourself, you earth and slime, and throw down yourself under all men's feet. Learn, I say, to break your will, and humbly to submit yourself to all. Wax hot against yourself, and suffer not pride to have place within you: but show yourself so lowly and simple, that all may tread you under foot like mire in the street.

The cultivated meekness promoted by the Christian conception of humility has been criticised by thinkers such as Hume (1740), Montaigne (2015), Nietzsche (1989), Spinoza (1994). Parts of their criticisms are nicely captured in literary form in the words of Sherlock Holmes:

My dear Watson,... I cannot agree with those who rank modesty among the virtues. To the logician all things should be seen exactly as they are, and to underestimate one's self is as much a departure from truth as to exaggerate one's own powers. (Doyle, The Greek Interpreter)

Holmes speaks of "modesty" rather than "humility" here. I suggest than we can read the above as treating modesty as synonymous with humility and will come back to the relation between the two concepts shortly.

Roberts and Wood $(2007,239)$ elaborate on Holmes' point:

if the excellent but modest person is presented with all the evidence of her excellences, she refuses to believe it. Thus the moral virtue of modesty is an intellectual vice.

Such a "virtue" is hardly appealing and so it is perhaps no surprise that interest in humility, once hailed by Prudentius and others as a heavenly virtue, began to fade. At the beginning of the millennium, Button (2005) asked "whatever happened to humility?", pointing out that whilst virtue theory was undergoing a revival in academic discourse, interest in humility was not similarly revived. Indeed, Konkola (2005, p. 198) remarks that not even contemporary Christian encyclopaedias provide entries for the virtue. Today, interest in the virtue has been renewed. Button (2005) discusses it in the context of political theory. More relevant to this paper is the academic discourse on the virtue by virtue epistemologists. Much of this discourse refers to a paper by Driver (1989).

For Driver (1989), an underestimation of the self, as in the Holmes quotation above, is part of modesty but not of humility. Ben-Ze'ev (1993, p. 240) and Nuyen (1998, p. 101) argue to the contrary: humility involves under-valuing oneself, but modesty does not. Tanesini (2018, 1n3) acknowledges the difference between modesty and humility in a footnote and adds that she will "follow the common 
practice of treating Driver's as an account of humility". And Roberts and Wood (2007) treat Driver's account of modesty as an account of humility without much ado. There is thus considerable disagreement about whether humility and modesty differ from one another and if so how. This paper does not attempt to settle this issue.

I suggest that the Christian conception of humility as a form of submission or selfnegation still has traction on the pre-theoretical conception of the virtue of some mathematicians. Consider Dirac:

If you are receptive and humble, mathematics will lead you by the hand. Again and again, when I have been at a loss how to proceed, I have just had to wait until I have felt the mathematics lead me by the hand. It has led me along an unexpected path, a path where new vistas open up, a path leading to new territory, where one can set up a base of operations, from which one can survey the surroundings and plan future progress. [quoted in (Farmelo 2009, p. 435)]

Notice how Dirac attributes to mathematics the status of the benevolent other; for him, mathematics is something that can take you by the hand. But this other is not merely a companion, it is a guide that can lead you out of your problems. For Dirac to be humble is to follow what he calls "mathematics". Mathematics for Dirac thus plays much of a similar role to the role of God in the Christian conception of humility.

A more recent example comes from a 2010 blog discussion on the n-category café website where mathematicians discussed vanity in mathematics. They cashed out one of its opposites, ${ }^{6}$ humility, as both a sense of "being small" and as having "a low regard for status". As user Todd Trimble beautifully put it:

We are also very lucky in that status always takes a back seat to logical correctness. It is a wonderful thing that if a graduate student points out a flaw in the argument of the illustrious Professor, the point must be quickly (and is usually graciously) admitted. ${ }^{7}$

Where Christians submitted to and were humbled by God, according to this narrative mathematicians submit to and are humbled by logical correctness. I will call this the Ms Bigshot and Mr Nobody narrative in later sections: when Mr Nobody points out a mathematical error in Ms Bigshot's proof, Ms Bigshot has to concede. It is part of the aim of this paper to argue against this narrative. In Sect. 4 I will argue that the here and now of proof assessment puts limits to the feasibility of the narrative. In Sect. 5 I show how Väänänen adjusts the reasoning structures of settheoretic practice to account for the intellectual pressures certain deeply held beliefs currently face; such adjustment is not submission.

\footnotetext{
${ }^{6}$ This aligns with Roberts and Wood (2007, p. 236), see below.

7 https://golem.ph.utexas.edu/category/2010/10/vanity_and_ambition_in_mathema.html, Accessed 15.1.2021.
} 


\subsection{Intellectual humility}

Intellectual humility has attracted considerable attention from virtue epistemologists in recent years (Whitcomb et al. 2017; Kidd 2016; Tanesini 2018; Hazlett 2012; Spiegel 2012; Roberts and Wood 2007; Driver 1989). This academic discourse is largely driven by ahistorical conceptual analysis which leaves little room for an understanding of the virtue as developing, changing, and context dependent. ${ }^{8}$ Such a culture of discourse suggests that intellectual humility is much the same across all epistemic endeavours. This paper is also a reaction against this trend. I elaborate on this in Sect. 6.

As mentioned in the introduction, virtue epistemologists tend to draw on thought experiments and, to a lesser extent, works of literature in their discussion of intellectual humility (and other virtues). They do not generally employ their accounts of the virtue in a study of concrete cases. It is a principal aim of this paper to employ some of the accounts of intellectual humility currently on offer to case studies of mathematical practices. To this end I present three accounts of the virtue, by Roberts and Wood (2007), Whitcomb et al. (2017), Kidd (2016), in this subsection without much discussion. I will then employ these accounts in my studies of cases of mathematical practices in the next sections. This will reveal where these accounts are successful at tracking manifestations of intellectual humility in an epistemic practice and instances where they fail to do so. The accounts will prove to be successful in some instances and unsuccessful in others. Employing these accounts in concrete case studies will also highlight a criticism raised by Whitcomb et al. (2017) of Roberts and Wood's (2007) account and contribute to that discussion.

My case studies in the following sections will reveal the relevance of social dimensions to understanding intellectual humility in mathematics. Below I will draw particular attention to the fact that all three accounts of intellectual humility presented in this section can accommodate (certain) social dimensions of epistemic practices. Throughout the sections that follow I will harvest these sensitivities to social concerns of the accounts of intellectual humility on offer for my discussion of the case studies I present.

Roberts and Wood (2007, p. 236) begin their discussion of intellectual humility by casting it as the virtue opposed to the following 14 vices: "arrogance, vanity, conceit, egotism, hyper-autonomy, grandiosity, pretentiousness, snobbishness, impertinence (presumption), haughtiness, self-righteousness, domination, selfish ambition, and self-complacency". They first discuss intellectual humility as opposed to vanity, then as opposed to arrogance, and then provide a general account of the virtue. In their discussion of intellectual humility as opposed to vanity they touch upon Driver's account of modesty, which Roberts and Wood (2007) read as an account of intellectual humility, and understand it as a dogmatic position to underestimate one's worth. Underestimation of one's worth was criticised in the Holmes quotation given above and Roberts and Wood show how

\footnotetext{
${ }^{8}$ A noteworthy exception is Kidd (2017).
} 
on this account the moral virtue of humility is an intellectual vice; "if the excellent but modest person is presented with all the evidence of her excellences, she refuses to believe it" (ibid. 239). To avoid this unhappy conclusion Roberts and Wood (2007) propose that:

the humble person is not ignorant of her value or status, but in a certain way unconcerned about it and therefore inattentive to it. (ibid. 239)

[intellectual humility] is an unusually low dispositional concern for the kind of self-importance that accrues to persons who are viewed by their intellectual communities as talented, accomplished, and skilled, especially where such concern is muted or sidelined by intrinsic intellectual concerns-in particular, the concern for knowledge with its various attributes of truth, justification, warrant, coherence, precision, load-bearing significance, and worthiness. Intellectual humility is also a very low concern for intellectual domination in the form of leaving the stamp of one's mind on disciples, one's field, and future intellectual generations. (ibid. 250)

On this account intellectual humility is neither submissive nor a cultivated meekness. Instead Roberts and Wood cut the conceptual space of epistemic activity between what they call "intrinsic intellectual concerns" and forms of praise, such as prizes, titles, reverence, followers, and so on. These forms of praise are part of the social dimensions of an epistemic practice. Roberts and Wood (2007) cast intellectual humility as a virtuous inattentiveness of an epistemic agent to these social dimensions.

In the next section I will read Roberts and Wood's as an account of intellectual humility about motivation: the intellectually humble are motived by "intrinsic intellectual concerns" rather than the prestige that may be attached to intellectual achievements. Roberts and Wood briefly touch upon this motivational theme in their discussion of Jesus of Nazareth, where they remark on Jesus' "unusually low concern for status coordinated with an intense concern for some apparent good" (ibid. 241), but do not develop it in greater detail.

Where Roberts and Wood (2007) tell us that the intellectually humble are in the right sort of way unconcerned with the forms of praise they may receive for their epistemic endeavour, Whitcomb, Battaly, Baehr, and Howard-Snyder give an account of how an intellectually humble agent comports herself in carrying out this epistemic endeavour (Whitcomb et al. 2017). For them, the intellectually humble own their limitations. According to them, to own one's limitations requires one not only be aware of one's intellectual limitations and weaknesses, but to acknowledge, admit to, and handle one's limitations in appropriate ways. They elaborate that.

owning one's intellectual limitations characteristically involves dispositions to: (1) believe that one has them; and to believe that their negative outcomes are due to them; (2) to admit or acknowledge them; (3) to care about them and take them seriously; and (4) to feel regret or dismay, but not hostility, about them. (ibid. 519) 
On this account the intellectually humble person does not underestimate the worth of her epistemic activity but handles her limitations in this activity in the right sort of way; an intellectually humble researcher might admit that his methodology can be criticised but nonetheless believe in the worth of his research findings.

Appropriate acknowledgement of one's limitations in the sense of Whitcomb et al. (2017) can be done privately; e.g. one might appropriately acknowledge one's inability to build a device even if alone on an island. Paradigmatically, however, such appropriate acknowledgement is a social affair and indeed most of the examples Whitcomb et al. discuss in their (2017) paper are situated in a social setting. The social dimension of epistemic activity is thus not germane to the account in the same way it is to Roberts and Wood's (2007) account, but Whitcomb et al.'s (2017) account of intellectual humility can nonetheless accommodate this social dimension.

Kidd (2016) proposes to understand intellectual humility as a two-component virtue. The first component is the ability to recognise when confidence conditions in beliefs are satisfied. He identifies three such conditions: (1) agential conditions, which include the agent's capacities, her education experiences and so on, (2) collective conditions, which include persons and collectives on which agents rely, and (3) deep conditions, which include cultural norms and convictions. According to Kidd, the intellectually humble person knows when she can trust her capacities for the task at hand, recognises the ways in which her epistemological actions rely on the abilities and contributions of others, and is aware of those deep-rooted beliefs that influence her thinking. However, to recognise that one satisfies these conditions poorly yet hold on to one's beliefs regardless is hardly humble. Therefore Kidd introduces a second component of the virtue: "a disposition to use the recognition of the relevance and fulfilment of confidence conditions to regulate the person's intellectual conduct" (2016, p. 397). Kidd remains somewhat vague on how the intellectually virtuous ought to regulate their intellectual conduct, which makes his account much more difficult to apply to concrete cases than those of Roberts and Wood and Whitcomb et al. On the other hand, Kidd's (2016) account of humility not only gets at social dimensions of epistemic practices but also touches on those in his words "deep" cultural forces that shape these practices. I employ Kidd's account in Sect. 5 to argue against the Christian-type conception of humility as submission to mathematical reasoning that the above-mentioned mathematicians suggest.

At this point in the paper I have presented three accounts of intellectual humility. These accounts present the virtue as pertinent to all forms of inquiry in a domain neutral way and are hence what Tanswell and Kidd (2020) call accounts of intellectual humility as a generic virtue. In the next three sections I will employ these accounts in a study of three cases in which intellectual humility (fails to) manifest. These case studies provide instances of (failed) manifestations of intellectual humility. As I will show, these instances of manifestation of the virtue are only partially captured by the accounts of intellectual humility as a generic virtue I presented in this section. I argue that this (a) invites the virtue epistemologists to adjust their accounts of the virtue to align more suitably with the instances of (failed) manifestation the virtue revealed in the three case studies and (b) suggests that a virtue theory of mathematical practices can learn from the accounts of the intellectual virtues as 
generic virtues as provided by virtue epistemology but should adjust them to the specific domain of inquiry under investigation, i.e. mathematical practices.

\section{The Erdős-Selberg dispute}

In this section I first introduce the well-known dispute about authorship between Atle Selberg and Paul Erdős. I then discuss the case in terms of the accounts of intellectual humility introduced in the last section. I argue that the dispute reveals two distinct but entangled dimensions of the virtue. I suggest how Roberts and Wood (2007) can draw on this entanglement to defend themselves against a criticism of their account of intellectual humility put forth by Whitcomb et al. (2017).

\subsection{The dispute}

Erdôs and Selberg disagreed about how the elementary proof of the Prime Number Theorem (PNT) should be published. Erdős insisted on a joint publication and Selberg insisted on separate, individual publications. They were unable to come to an agreement.

PNT is a statement about the distribution of prime numbers and hence part of number theory. It was proven independently by Hadamard and de la Vallee Poussin in 1896. These proofs rely on complex analysis and thus extend beyond the confines of number theory. The mathematical lingo for this is that these proofs are not elementary. In 1921 Hardy remarked: ${ }^{9}$

If anyone produces an elementary proof of the prime number theorem, he will show that $[\ldots]$ the subject does not hang together in the way we have supposed, and that it is time for the books to be cast aside and for the theory to be rewritten.

An elementary proof of PNT thus promised prestige. Selberg's and Erdős' dispute over how to publish the proof was hence also a dispute over who would earn this prestige.

Atle Selberg defended his doctoral thesis in October 1943 in Norway. The German invasion then stifled his career until Carl Ludwig Siegel encouraged him to apply for a 1-year position at the Institute for Advanced Studies in Princeton, USA, which was successful and where Selberg spent the academic year 1947-48 (Selberg and Devine 1989, p. 10). He was offered a 1-year continuation at Princeton but decided to move to Syracuse instead. The events that led to his dispute with Erdős took place in this transition period in 1948-49. Notice that at the time of the events Selberg was still a young and relatively unknown mathematician who was looking for a permanent position.

\footnotetext{
${ }^{9}$ In a lecture delivered to the Mathematical Society of Copenhagen. Quotation taken from Goldfeld (2004, p. 3).
} 
Paul Erdős is renowned today as a mathematical genius, problem-poser, and as the travelling mathematician who would expect his collaborators to host and feed him (Hoffman 1998). In the 1930s Erdôs held a fixed-term position at the Institute for Advanced Studies in Princeton but Herman Weyl, who disapproved of Erdős' eccentric style, had vetoed a renewal of Erdős' grant (Spencer and Graham 2009). Erdős continued to travel, pose problems, and prove theorems. By 1948 he was already a well-known mathematician and decided to visit the institute in Princeton in July.

The following account of the events is pieced together primarily from recounts of those who had emotional stakes in the events. Where there are disagreements, I have tried to point them out.

In early 1948 Selberg was working on his proof of Dirichlet's theorem, in which he developed the by now well-known sieve method. In May of that year Selberg finished writing up a sketch of his proof but did not consider it ripe for publication. In July Pál Turán asked Selberg if he might see these sketches. Selberg not only showed them to Turán but willingly walked him through his work. In this connection Selberg also mentioned the so-called fundamental formula but recalls that he "did not tell him [Turán] the proof of the formula, nor about the consequences it might have and my ideas in this connection". ${ }^{10}$ Selberg then left for Montreal. He wanted to apply for a permanent visa to the USA, which required him to leave the country. Whilst Selberg was gone, Turán gave a seminar on Selberg's results. In Straus' recollection, Selberg had suggested to Turán to give this seminar (Spencer and Graham 2009). Selberg remembers it differently: ${ }^{11}$

It turned out that Turán had given a seminar on my proof of the Dirichlet theorem where Erdős, Chowla, and Straus had been present. I had of course no objection to this, since it concerned something that was already finished from my side, though it was not published. In connection with this Turán had also mentioned, at least to Erdős, the fundamental formula, this I don't object to either, since I had not asked him not to tell this further.

During the seminar Erdős conjectured that from Selberg's fundamental formula one could deduce $\mathrm{p}(\mathrm{n}+1) / \mathrm{p}(\mathrm{n}) \rightarrow 1$, an important step towards an elementary proof of PNT. Erdős communicated this conjecture and his attempts to prove it to Selberg on Thursday, 15.7.1948, the day after Selberg's return from Montreal. ${ }^{12}$ Selberg, by his own admission, ${ }^{13}$ tried to discourage Erdős from attempting to prove the conjecture and aimed to throw him off track by presenting a would-be counter-example which, whilst satisfying two necessary conditions, failed to satisfy a third such condition.

\footnotetext{
${ }^{10}$ From Selberg's letter to Weyl of 16.9.1948, published in Goldfeld (2004, p. 184).

11 Selberg explicitly denies that he had asked Turán to give the seminar in his letter to Goldfeld from 6.1.1998, published in Goldfeld (2004, p. 185). The quotation is from Selberg's letter to Weyl of 16.9.1948. Published in Goldfeld (2004, p. 184).

12 These dates are taken from Selberg's recollection of the event as presented in his letter to Goldfeld from 6.1.1998, published in Goldfeld (2004, p. 185).

13 In his letter to Goldfeld from 6.1.1998, published in Goldfeld (2004, p. 185).
} 
Selberg also neglected to tell Erdős about an equality he, Selberg, could already prove. This equality is $\mathrm{a}+\mathrm{A}=2{ }^{14}$ Selberg knew already in May of that year that if he could show that $\mathrm{a}=\mathrm{A}=1$, then he could produce an elementary proof of the Prime Number Theorem. "I [Selberg] kind of tried to scare him [Erdős] away from the prime number theorem itself. It was, one may say, a little dishonest that I did not tell him that my counterexample was based on a non-monotonic function" (Baas and Skau 2008, p. 646).

By Friday Erdős had a proof of a slightly stronger result than $p(n+1) / p(n) \rightarrow 1$, which he communicated to Selberg. On Sunday Selberg produced a first version of an elementary proof of PNT, which made use of Erdős' result, and communicated this to Erdős on Monday. Erdôs suggested to discuss the results in a seminar later that evening. Selberg recalls:

It turned out that Erdôs had announced this at the university so instead of the small informal gathering that I thought this was supposed to be, the auditorium was packed with people. I went through the first parts that I had done earlier. Then Erdős went through what he had done. Finally, I completed the proof of the Prime Number Theorem by combining his result with mine. (Baas and Skau 2008, p. 643)

Selberg then left for Syracuse. He had to teach and look for an apartment, so announcements of his results on PNT to the wider mathematical community would have to wait. Erdős was not of a mind to wait. Straus recalls the events after the seminar:

When we got home, too excited to go to sleep, Erdôs and I discussed for some time the best way to spread the word. We both realized that at that time Erdős was far better known than Selberg and - at least in Erdő's' mind - the elementary proof was a direct outgrowth of Selberg's fundamental inequality, and Erdős' own contribution, although important, would not have been possible without that inequality. After lengthy discussion, we arrived at a formulation that Erdős used in the scores of postcards that he sent all over the world. I believe I remember the formulation verbatim "Using a fundamental inequality of Atle Selberg, Selberg and I have succeeded in giving an elementary proof of the Prime Number Theorem.', (Spencer and Graham 2009)

Selberg became aware that some members of the community only mentioned Erdős' name in connection with the elementary proof of $\mathrm{PNT}^{15}$ and wrote him a letter on

\footnotetext{
${ }^{14}$ Hereby a is the $\lim$ inf and $A$ the $\lim$ sup of $d(x) / x$, where $d(x)$ is the sum of the logarithms of all primes less than $\mathrm{x}$.

15 Straus' story about somebody telling Selberg that "Erdős and some other guy" found an elementary proof of PNT seems to be exaggerated. For Straus' story see (Spencer and Graham 2009), for Selberg's answer see (Goldfeld 2004).
} 
how to proceed. At the time Selberg had already redesigned his proof such that the new proof no longer relied on Erdő's result. Nonetheless, Selberg suggested to Erdős to publish his result first, mentioning the parts of Selberg's work his result relied on. Then Selberg would publish the elementary proof of PNT, giving a sketch of the original elementary proof of PNT which relied on Erdő' result and then the redesigned elementary proof of PNT which does not rely on Erdős' work. Erdős, in discussion with Strauss, had come to a different conclusion. He thought that Selberg should publish alone on his fundamental formula, followed by a joint article in which Erdős would prove his result and Selberg then give the elementary proof of PNT. On September 20 Selberg wrote to Erdős:

"I hope also that we will get some kind of agreement. But I cannot accept any agreement with a joint paper.

Erdős replied on September 27:

[I] completely reject the idea of publishing only [my result] and feel just as strongly as before that I am fully entitled to a joint paper

Since no friendly agreement could be reached, both mathematicians submitted separate papers. Erdős' submission to the Bulletin was entitled "On a new method in elementary number theory which leads to an elementary proof of the prime number theorem". In it, Erdős points out the importance of Selberg's work and his new elementary proof which does not rely on Erdős' result. The work was reviewed by Weyl, who wrote an extensive letter to the referee Nathan Jacobson stating ${ }^{16}$ :

Erdôs is scrupulously fair in giving Selberg his due credit. But has he the right to publish things which are admittedly Selberg's, but which the latter considers intermediary and therefore not fit for publication?

Weyl nonetheless saw possibilities for publication, given certain changes are made. For example, he believed the title should change to "Report on the development on a new elementary method in number theory" because "it would indicate that the paper reports on something which the author can only partially claim as his own product". Jacobson communicated to Erdős that the reviewer does not recommend publication. Erdôs retracted the paper and published in the Proceeding of the National Academy of Sciences instead.

After the initial presentation at the seminar in Princeton Selberg never lectured on the elementary proof of PNT again. Erdős did. In the year of these events, 1948, he lectured in Amsterdam. Van der Corput was present at these lectures and wrote up an outline of the proof. This outline became publicly available in autumn that year and was the first published version of an elementary proof of PNT.

$\overline{16}$ Letter printed in (Baas and Skau 2008, p. 139). 


\subsection{Discussion}

The above material allows for various readings, including as a dispute between Selberg and Erdős on whose name would be attached to the prestigious elementary proof of PNT and as a dispute about the proper ways to recognise the intellectual contributions of the mathematicians to the proof. In none of these readings is the quality of the proof in question. What is at stake are what MacIntryre (1981) calls goods external to the practice, such as fame or recognition, rather than internal goods, such as the correctness of the proof.

On Roberts and Wood's (2007) account the intellectually humble person is virtuously inattentive to external goods that connect to social status. Since neither Erdôs nor Selberg were inattentive to these external goods, neither of them manifested intellectual humility in their dispute on this account. Whitcomb et al. (2017) have criticised Roberts and Wood, pointing out that one can be intellectually humble even though one is concerned with external goods - they give the example of a female worker who is aware of and responds appropriately to her intellectual limitations but who is at the same time concerned about the social status she holds in her maledominated profession. The Erdős-Selberg dispute may be a real-life case in point. Both mathematicians own their limitations in their pursuit of the internal good of finding a correct elementary proof of PNT, even though both were concerned with goods external to their mathematical practice (number theory in this case) when it came to publishing their results.

Dividing up the conceptual space into the pursuit of internal and external goods of an intellectual practice may tempt us to think, akin to Whitcomb et al., that intellectual humility manifests in the pursuit of internal goods. The pursuit of external goods would then not be sufficiently epistemic for intellectual humility to manifest. But this assumes a robustness of the distinction between internal and external goods which is not warranted. The promise of external goods may be the motivation for pursuing internal goods. Roberts and Wood are right in pointing out that the promise of some kinds of external goods, such as fame and glory, do not motivate the intellectually humble in their epistemic activity. This is not to say that all external goods should be disregarded; Whitcomb et al.'s female worker may be intellectually humble even though she pays attention to her social status. Roberts and Wood remind us that motivation by certain external goods conflicts with intellectual humility.

The elementary proof of PNT promised prestige and fame because it promised deep new insights into number theory. Hardy thought it would force "the theory to be rewritten". ${ }^{17}$ The elementary proof of PNT was thus an internal good of the intellectual practice of number theory. More so, it was a valued and prized internal good. And because it was so valued it promised external goods such as fame and prestige. These external goods are deeply entangled with the internal goods in this case.

\footnotetext{
17 Hardy misjudged this. The impact of the elementary proof of PNT on number theory turned out to be minor.
} 
The intellectually humble pursue the goods internal to their intellectual practice because they submit in the right kind of way to the demands of their practice, not because of the promise of some external goods such as fame or prestige. In this sense neither Selberg nor Erdős was intellectually humble in their dispute. Selberg tried to lead Erdôs astray to get him off the track of the elementary proof. Erdős, in his colourful language explored in (Hoffman 1998), is said to have told Siegler in connection with the elementary proof of PNT "What I want is immortality" (Baas and Skau 2008, p. 131). Krantz $(2010,217)$ recounts the following anecdote:

Irving Kaplansky (1917-2006) was in residence at the Institute for Advanced Study in those days and witnessed the feud in some detail. He tells me that at one point he went to Erdős and said, "Paul, you always say that mathematics is part of the public trust. Nobody owns the theorems. They are out there for all to learn and to develop. So why do you continue this feud with Selberg? Why don't you just let it go?" Erdős's reply was, “Ah, but this is the prime number theorem".

These remarks indicate that the two mathematicians were at least partly motivated in their dispute by the promise of fame. Roberts and Wood are right to point out that this does not make for an intellectually humble agent.

Motivation by certain external goods may be a sign of proper pride. The virtuously proud demand recognition of their intellectual activity in the right kind of way; Whitcomb et al. (2017, p. 516) call this having the right stance towards one's intellectual strengths. Selberg had reason for such pride. He needed to get his academic career started and recognition for such a prestigious result as the elementary proof of PNT would be of much help. We should criticise him for the means of deceit he employed to defend his intellectual property, ${ }^{18}$ but the act of defending his major result may be praiseworthy-even if it is not intellectually humble.

\section{The abc-conjecture}

In the last section I discussed the Erdős-Selberg dispute which helped to draw out the difference between the pursuit of goods internal to an intellectual practice, such as the truth of a theorem, and the pursuit of external goods, such as the prestige attached to proving certain theorems. From Roberts and Wood (2007) I took the idea that the intellectually humble are not motivated to pursue internal goods by the promise of social status (i.e. a certain type of external good). From Whitcomb et al. I took the suggestion that Roberts and Wood's account is not enough to cash out intellectual humility because it lacks a story about how to pursue internal goods in an intellectually humble way. In this section I take up Whitcomb et al.'s point and explore intellectual humility in the pursuit of goods internal to mathematical practices.

\footnotetext{
${ }^{18}$ Interestingly, Prudentius already connected humility, pride, and deceit in his Psychomachia; see Sect. 2.
} 
Recall here the Ms Bigshot and Mr Nobody narrative mentioned in Sect. 2: when Mr Nobody finds a mistake in Ms Bigshot's mathematical proof, Ms Bigshot has to concede. Notice how appealing this narrative is. It gets at the seemingly inescapable force of mathematical reasoning. But also notice how strange it is to understand this as a narrative about humility in mathematics (as happened on the n-category café blog, see Sect. 2). If mathematical correctness guaranteed intellectual humility in the assessments of mathematical proofs, then there would be a tool that ensures a certain kind of excellence of intellectual character. But this is not how virtues function. Virtues are too soft to be brought about by any tool-like machinery. They are not the kind of thing that one can manifest by following precise or even machine-implementable rules. This is perhaps most clearly seen from the fact that it can sometimes be praiseworthy not to manifest a certain virtue. Manifesting openmindedness towards abhorrent views can display the vice of indifference; manifesting courage can be foolhardy; and perhaps Selberg was virtuous in not manifesting humility but proper pride in his dispute with Erdős.

If we take the softness of the virtues seriously, then, despite an initial appeal of the account, mathematical reasoning does not ensure intellectual humility. There should thus be instances of mathematical practices that do not align with the Ms Bigshot and Mr Nobody narrative. This is obvious for short timeframes because Ms Bigshot may need a moment to understand her mistake. But what I am after here are disagreements about the correctness of a proof that persist even after both Ms Bigshot and Mr Nobody have spent a sufficient amount of time and effort to make their case forcefully. Such cases of disagreement are relatively rare. One example is the case of Kurt Heegner, who maintained that his solution to the class number problem in number theory was correct even when the mathematical community regarded his proof as fatally flawed. Only after Heegner's death did opinions change. Today, Heegner's work is regarded as correct, Roberts (2019), van der Poorten (1996), Coates (1984).

In this section I discuss another case in which the Ms Bigshot and Mr Nobody narrative does not align with actual practice: the case of the abc-conjecture. Mochizuki has proposed a proof, Scholze argues that it is flawed, but Mochizuki disagrees. In this section I present this debate in some detail to draw out how intellectual humility in proof appraisal can fail.

\subsection{The disagreement}

Shinichi Mochizuki is a prodigy mathematician. He became an undergraduate student at the Princeton mathematics department when he was only 16 years old and obtained his $\mathrm{PhD}$ at the age of 23. Two years later, in 1994, he joined the Research Institute for Mathematical Sciences (RIMS) at Kyoto University and was promoted to professor in 2002. He earned the respect of the international mathematical community $^{19}$ and is known as a careful and deep thinker. In August 2012 he uploaded

\footnotetext{
19 Witnessed by, for example, his proof of a conjecture by Groethendieck on anabelian geometry (1996) and his invited talk at the International Congress of Mathematicians in 1998.
} 
four papers, around 500 pages in total, to his web page. In these papers he introduces what he calls Inter-Universal-Teichmüller (IUT) theory and applies it to prove the abc-conjecture. ${ }^{20}$

The abc-conjecture states that for every $\varepsilon>0$ there are only finitely many triples $(a, b, c)$ such that $a, b, c$ are positive co-prime integers, $a+b=c$ and $c>d^{1+\varepsilon}$, where $d$ is the product of the distinct prime-factors of a, b, and c. An example of such a triple is $5+27=32$, where $\mathrm{d}=5 \times 3 \times 2=30$. This example only works for very small $\varepsilon$, as $30^{1.02}$ is about 32.11 and hence bigger than $c=32$. The abc-conjecture is also known as the Oesterlé-Masser conjecture; Oesterlé first mentioned it in a talk in 1985 and Masser recognised its far reaching potential and publicised it. For example, Elkies (2007) showed that if true, the abc-conjecture would put an upper bound on the number of solutions to certain Diophantine equations. This would limit the possible solution-space for these equations, thereby allowing for exhaustive brute-force (i.e. "doable") calculations to solve entire collections of thus far unsolved equations.

Even though Mochizuki did not publicly announce his proposed proof of the abcconjecture, word of his uploaded pre-prints spread quickly around the mathematical world. However, mathematicians who tried to read the proof soon became bewildered by it. "Looking at it, you feel a bit like you might be reading a paper from the future, or from outer space" wrote Jordan Ellenberg on his blog. Ivan Fesenko, an expert in the field, elaborates: "The actual length [of the proof] is about 550 pages. But to understand [Mochizuki's] theory, one also has to know well various appropriate prerequisites, so we are talking, approximately, about 1000 pages of prerequisites and 550 pages of IUT theory" (Crowell 2017). Even for those who know the relevant prerequisites, Mochizuki's proof is difficult to digest, as one who knows much of these prerequisites, Brian Conrad, tells us:

The manner in which the papers culminating in the main result has been written, including a tremendous amount of unfamiliar terminology and notation and rapid-fire definitions without supporting examples nearby in the text, has made it very hard for many with extensive background in arithmetic geometry to get a sense of progress when trying to work through the material. There are a large number of side remarks in the manuscripts, addressing analogies and motivation, but to most readers the significance of the remarks and the relevance of the analogies has been difficult to appreciate at first sight. As a consequence, paradoxically many readers wound up quickly feeling discouraged or confused despite the inclusion of much more discussion of "motivation" than in typical research papers. In addition to the difficulties with navigating the written work, the author preferred not to travel and give lectures on it, though he has been very receptive to questions sent to him via email and to speaking with visitors to RIMS. (Conrad 2015)

\footnotetext{
${ }^{20}$ Mochizuki also presents proofs of the strong Szpiro conjecture and the hyperbolic Vojta conjecture. This paper, as much of the discussion surrounding Mochizuki's papers, focusses on the proof of the abcconjecture.
} 
According to Conrad, Mochizuki's proof is difficult to digest because from the proof presentation mathematicians struggle to identify a striking new idea and a sense of how this idea is up to the task of solving the issue at hand. ${ }^{21}$ As Conrad (2015) tells us, this feeling was shared by many attendees of a 2015 week-long workshop in Oxford, UK, at which numerous mathematicians got together in the hopes of making progress towards understanding Mochizuki's proof. The workshop did not make enough progress, despite Mochizuki's skype'd-in Q\&A sessions, to meaningfully assess the correctness of the proof.

Mochizuki's prior work commands significant respect and this is at least part of the reason why mathematicians are willing to invest so much effort in understanding his proof. By the end of 2015 the mathematical community had invested three years and a dedicated workshop, but Mochizuki's proof remained impenetrable to most. Many agreed that essential aspects of the communication of mathematical results had failed. There was a felt need for a survey paper, by Mochizuki or someone else, that would lay out the relevant mathematics more clearly. Yamashita (2017), a colleague of Mochizuki, provides such a survey. It is itself 294 pages long and seems to have done little to alleviate the problems surrounding Mochizuki's proof.

Peter Scholze is another prodigy mathematician. He won the Fields medal in 2018. When Mochizuki's papers appeared in 2012 Scholze read them and was bemused by the long and technical theorems with very short proofs which struck him as "valid but insubstantial" (Klarreich 2018). Corollary 3.12 in the third paper is different. The proof is nine pages long and the result plays a key role in the abcproof. Scholze could not, by his own admission, follow the logic in these nine pages (ibid.). He was only 24 at the time and decided not to contribute to public debate about Mochizuki's proof then. But when Conrad published the above-mentioned blog post in 2015 Scholze sent Conrad an unsolicited email about his concerns with Corollary 3.12. As Conrad mentions in a reply to (Calegari 2017), two other mathematicians had similar doubts about 3.12 and wrote unsolicited emails to Conrad. Shigefumi Mori contacted Scholze to organise a meeting between him and Mochizuki. Scholze reached out to Jakob Stix and together they spent one week in March 2018 in Kyoto to discuss the abc-proof with Mochizuki and his colleague Yuichiro Hoshi. The discussion remained inconclusive: Mochizuki and Mori maintain that the proposed proof of the abc-conjecture is correct, Scholze and Stix argue that it is flawed; (Scholze and Stix 2018; Mochizuki 2019).

The principal disagreement is about certain isomorphisms, called poly-isomorphisms, used in Mochizuki's proposed proof. As Roberts (2019) puts it, Scholze and Stix "have allowed themselves to identify isomorphic objects for the purpose of simplifying an argument. In places where Mochizuki supplies two distinct but isomorphic mathematical objects, Scholze and Stix see only one on the grounds that they are isomorphic." Mochizuki denies that such identification can be done. He argues that there is a "fundamental misunderstanding" on the part of Scholze and Stix

\footnotetext{
${ }^{21}$ In a reply to Calegari's (2017) blog post Terrence Tao points out the value of what he calls "proofs of concept statements", by which he means "ways in which the methods in the paper in question can be used to obtain new non-trivial results of interest".
} 
and their criticism "does not imply the existence of any flaws in IUT whatsoever" (Mochizuki 2019, 1). In a recent blog post Taylor Dupuy (2020) explains some of the mathematical details that may be involved in this "fundamental misunderstanding". In his answer to Dupuy's post, Scholze stresses that he is "willing to accept that there is a nonzero chance that some of these things might make sense under certain circumstances" but demands of Mochizuki to be clearer about the matter. As things stand, Scholze maintains that Mochizuki's proof is flawed.

Mochizuki (2013) remarks that the initial four papers were submitted to a journal but does not provide the name of that journal. There was a rumour that the journal was the Publications of the Research Institute for Mathematical Sciences (PRIMS), the in-house journal of RIMS. Mochizuki is chief editor of PRIMS. Notice that mathematicians often submit to journals of which they are editors (Castelvecchi 2020). As long as they do not get involved in the reviewing process, this is considered acceptable. For example, it does not conflict with the ethical codes of the European Mathematical Society. Nonetheless, PRIMS denied at the time that Mochizuki had submitted his papers to the journal.

On 3 April 2020 it was announced that PRIMS will publish Mochizuki's proof. Kiran Kedlaya, an expert who has spent considerable effort to penetrate Mochizuki's proof, remarks "I think it is safe to say that there has not been much change in the community opinion since 2018" (Castelvecchi 2020). The epistemic status of the abc-conjecture remains disputed. Some mathematicians agree with Mochizuki and the PRIMS reviewer that the proposed proof is indeed correct. Scholze ${ }^{22}$ and other mathematicians maintain that the proof is flawed. And many mathematicians seem to suspend judgement for now.

\subsection{Discussion}

The disagreement between Mochizuki and Scholze is about what follows from a given mathematical set-up. It shows that what counts as a mathematical mistake in a proof can itself be a matter of dispute. Bloor (1976) made a very similar point, invoking an indigenous African culture whose logic does not align with those logical standards which are widely accepted in contemporary mainstream mathematics. He used this to argue that even the logical force of mathematics is a social construct. I do not make such radical social constructivist claims. I wish to draw attention to the fact that in the here and now of humans handling mathematical texts, the question of what amounts to a mathematical mistake can be a matter of dispute. It is in this here and now that mathematicians act and thus it is in this here and now that mathematicians may (fail to) manifest intellectual virtues such as humility.

When proofs become so complex and difficult to understand that even experts struggle, the reasoning structures of mathematics can fail to function in their usual and expected ways. In cases where this happens, such as in the case of the

\footnotetext{
22 Stix has refused comment for Castelvecchi's piece. He has also not (openly) contributed to the blog discussion between Scholze and Dupuy mentioned above.
} 
abc-conjecture, there is room for disagreement about the mathematical correctness of a proof.

Maddy $(1997,2011)$ argues that set theory can serve as a final court of appeal for matters about the correctness of proofs. Whilst there is a case to be made that it is a goal of set theory to provide such a service (see also Sect. 5), other mathematical disciplines do not generally make use of this service. In the abc-conjecture case some experts struggle to understand the proof. The ability to translate the proof into a set-theoretic idiom and (more easily?) check its correctness there seems beyond reach. Roberts (2019) makes a similar point about computer assisted proof checkers.

Mochizuki uploaded his initial papers 8 years ago. During this period the mathematical community has critically remarked on Mochizuki's proof-communication. His writing has been criticised for: unfamiliar terminology; definitions without nearby examples in the text; large number of difficult to process side-remarks; motivation parts are obscure. Mochizuki has furthermore been criticised for refusing to travel outside of Japan to lecture on the proof. All these are limitations to Mochizuki's efforts to communicate his proof to the mathematical community in a way that fosters understanding. According to the account of intellectual humility by Whitcomb et al. (2017), Mochizuki should "own his limitations". He should admit to them and overcome them where he can, for example by writing a concise survey paper or by lecturing on his proof to international audiences. This he has refused to do. The year after uploading his papers Mochizuki $(2013$, 5) remarked that "if one proceeds to study carefully step by step, starting from the 'preparatory papers', there is no reason that one should encounter any insurmountable difficulties" in understanding the proof of the abc-conjecture. Over the years that followed Mochizuki was responsive to emails (by experts, he avoids journalists), has skypedin to international meetings, and has communicated his proof to colleagues and visitors at RIMS. None of these efforts were sufficient to transmit an understanding of his proof to the international mathematical community. This raises the question how far the intellectually humble need to go to own their limitations.

Whitcomb et al.'s (2017) account of intellectual humility remains silent on the question how far one needs to go to own one's limitations. Yet an answer may not be far off. It may not be enough to own one's limitation; one may also need to ensure that the way one attempted to own one's limitation was successful in what it aimed to achieve. The steps Mochizuki undertook to generate understanding were unsuccessful. We may thus expect him to undertake further steps until his intellectual aims are reached. Intellectual humility might be best understood as containing such a success condition.

Notice that there are good reasons to stop owning one's imitations. Additional communication of his proof would require an amount of time and effort on Mochizuki's part that may not align with his life plans. Extended travel outside of Japan may be detrimental to his local social network and personal wellbeing; writing survey papers is time-consuming and possibly detrimental to his other intellectual projects. How much can reasonably be expected? When we understand intellectual humility as a virtue in service of the intellectual flourishing of the practice, then no such personal concerns should deter Mochizuki. If we understand intellectual humility as a virtue in the service of the intellectual flourishing of an individual, then such 
personal concerns will be important. Demanding to own one's limitations thus also raises questions about how much self-sacrifice for the intellectual practice can be demanded.

There is a noteworthy symmetry to intellectual humility in the abc-case. Above I explored how Mochizuki's critics demand that he manifest more intellectual humility by going further in owning the limitations of his communicative efforts to foster understanding of his abc-proof. Mochizuki counters by demanding that his critics manifest more intellectual humility in their engagement with his proof. Mochizuki (2013) saw "no reason that one should encounter any insurmountable difficulties" with his proof, provided one is diligent enough in preparing for its study. Mochizuki (2019) adds that criticisms of IUT theory lacked well-defined, detailed and mathematically substantive content. Scholze's and Stix's points were the first exception. However, they allowed themselves to identify two objects that need to be kept distinct according to Mochizuki (see the point about poly-isomorphisms above). In all these instances Mochizuki points out some intellectual limitations of his critics. Neither Roberts and Wood (2007), nor Kidd (2016), nor Whitcomb et al. (2017) offer considerations on such symmetric cases of intellectual humility.

Dutilh Novaes (2020, chapter 11) accounts for the symmetry in the abc-case. She presents the case as an instance of the adversarial collaboration in her Prover-Skeptic model breaking down. Prover, Mochizuki, has failed in his functional duty to convince Skeptic, his audience, of the correctness of his proof. On the other hand, Prover (Mochizuki) claims that Skeptic has (largely) failed in her functional duties because she does not understand IUT theory enough to count as relevant audience.

Dutilh Novaes' analysis forcefully raises questions about the relevant audience for proofs. Who gets to disagree on the alleged mathematical correctness of a result? The Mr Nobody and Ms Bigshot narrative would have it that everybody, even a Mr Nobody, gets to have a say. This now appears as too idealised. Only if Ms Bigshot attributes some relevant expertise to Mr Nobody about the piece of mathematics in question will she be disposed to revise her proof. Mr Nobody is thus not a nobody after all. He counts as relevant expert to Ms Bigshot, which is to say that Ms Bigshot treats Mr Nobody as having a relevant social status. When assessing a mathematical proof both author and reviewer ought to be attentive to the social status of those engaging with a proposed proof; it is good practice to filter the opinion of cranks from the criticism of experts. This jars with Roberts' and Wood's (2007) account of intellectual humility: if the intellectually humble were always inattentive to social status, then the intellectually humble would make for bad assessors of mathematical proofs.

I began this section with a critique of the proposal that intellectual humility in the appraisal of mathematical proofs may be ensured by a tool-like machinery of mathematical reasoning. In this section I showed how matters of proof presentation and of expertise play a significant role in proof appraisal and argued that intellectual humility may fail to manifest in these facets of mathematical practices. I left aside, however, questions about the force of mathematical reasoning. As developed in Sect. 2, Dirac and the mathematicians from the n-category café blog discussion suggest a Christian conception of humility in mathematics as submission to the force of mathematical reasoning. In the next section I show how Väänänen's development of 
multiverse logic adapts mathematical reasoning structures to the intellectual pressures his practice currently faces in an intellectually humble way. This challenges the conception of humility as a form of submission in mathematics.

\section{The set-theoretic pluralism debate}

Recall from Sect. 2 that Kidd (2016) discusses intellectual humility in terms of confidences. Part of what Kidd calls "deep confidences" are the kind of confidences we may have into the intellectual enterprises we are embarked upon. The intellectually humble agent regulates her intellectual conduct in recognition of the relevance and fulfilment of confidence conditions. In particular, an intellectually humble agent is disposed to recognise her deep confidences and is willing to review them should intellectual pressures demand it. Kidd (2016, p. 398) insightfully remarks that "the vices that mark a lack of humility, such as arrogance and dogmatism, are often characterized in terms of their closing a person off from the possibility of intellectual engagement with others". ${ }^{23}$

In Kidd's framework, the intellectually humble mathematician is disposed to recognise when her deeply held beliefs in the reasoning structures of her practice come under pressure and is willing to revise them where intellectual pressures demand it. Lakatos' (1976) Proofs and Refutations is one narrative about what forms such intellectual pressures on mathematical reasoning structures may take and how mathematicians have adjusted their reasoning structures accordingly. In this section I present Jouko Väänänen's development of multiverse logic as another example.

Väänänen is a set theorist and set theory is currently facing notable intellectual pressure on the basic assumption that set theory's epistemic grasp extends to every mathematical proposition. I call a proposition within our epistemic grasp if the truth-value of the proposition is already known or can be known in the future, either through proof or on the basis of some other reasons (e.g. what Gödel (1947) called intrinsic and extrinsic reasons). Propositions which are not within set theory's epistemic grasp are the absolutely undecidable propositions (see below). Set theorists today are having a debate about whether there are such absolutely undecidable propositions, i.e. whether the epistemic grasp of set theory is limited. Väänänen proposes to adapt the reasoning structures of set theory to handle the intellectual pressures on the assumption that set theory's epistemic grasp is unlimited: he proposes a new logic, multiverse logic, which can formally capture the view that certain mathematical statements are beyond our epistemic grasp. Set theorist and philosopher Juliette Kennedy (2015) has called Väänänen a border-crossing logician:

Of course, not all logicians are attracted to dogma. Some are fascinated by the space between theories, by points of data downplayed by this or that theoretical stance, or left out altogether. Their approach is pantheistic and ecumeni-

${ }_{23}$ Kidd credits (Tiberius \& Walker 1998) for this insight. 
cal, and, with respect to foundations in particular, opportunistic and localized. Their attitude is critical, not toward any particular logical method, but toward the idea of omniscience. Neutrality is not a goal in itself; border- crossing logicians are willing to take ideology seriously where they find it effective-it is just that they rarely find it so. (Kennedy 2015, 1)

I argue that Väänänen manifests intellectual humility in the way he proposes to adapt the old set-theoretic dogma that all mathematical statements are within our epistemic grasp to the intellectual pressures this dogma is currently facing.

\subsection{Multiverse logic}

Set theorists are currently having a debate about the fundamentals of their field. Part of this debate is about pluralism. Roughly, the monists hold that there is a single structure containing all sets, the so-called true universe of sets. The pluralists argue, again roughly, that there is no one structure that should (or even can) be granted this special status.

Maddy $(2017,2011,1997)$ has given a career-length argument that set-theoretic monism is the orthodoxy in set theory in the sense that monism can be assumed, pluralism needs to be argued for. ${ }^{24}$ As she convincingly argues, set-theoretic practice was also intended to serve as a foundation for all of mathematics. To satisfy set theory's foundational goal, Maddy argues that a single unified structure in which all sets appear is preferable.

Criticism of Maddy has focussed on her claim that set theory today should still be committed to monism (Ternullo 2019), ${ }^{25}$ (Rittberg 2016), (Antos et al. 2015). Her argument that set-theoretic monism is the orthodox position in the current settheoretic pluralism debate is not in doubt.

The set-theoretic pluralism debate arose, in part, out of the realisation that some set-theoretic propositions are undecidable from the currently accepted axiom system Zermelo-Fraenkel with Choice, ZFC for short. A proposition is called undecidable from some axiom system if that axiom system neither proves nor disproves the proposition. The well-known example is the Continuum Hypothesis, $\mathrm{CH}$, which is undecidable from ZFC. Notice that undecidability is a formal notion: set theorists can prove that $\mathrm{CH}$ is undecidable from $\mathrm{ZFC}$. But of course, $\mathrm{CH}$ is decidable in certain axiom systems that are stronger than $\mathrm{ZFC}$, e.g., $\mathrm{ZFC}+\mathrm{V}=\mathrm{L}^{26}$ To decide $\mathrm{CH}$ thus requires rational argument for such a stronger axiom system. ${ }^{27}$ An undecidable proposition is called absolutely undecidable if there can be no such rational argument.

\footnotetext{
${ }^{24}$ Note that it is questionable whether monism is the most commonly held position amongst set theorists today. See (Rittberg 2020) for more on monism as the orthodoxy of contemporary set theory.

25 See also Maddy's (2019) reply to Ternullo.

${ }^{26} \mathrm{~L}$ is Gödel's constructible universe. "V=L" is a formal rendering of the idea that every set is constructible in the $\mathrm{L}$-sense. Since $\mathrm{CH}$ provably holds in $\mathrm{L}, \mathrm{ZFC}+\mathrm{V}=\mathrm{L}$ proves that $\mathrm{CH}$ is true.

27 For example, one would have to find rational and convincing arguments for accepting the axiom $\mathrm{V}=\mathrm{L}$. There are many rational arguments to the contrary and many (if not most) set theorists today do not grant $\mathrm{V}=\mathrm{L}$ the same status as the $\mathrm{ZFC}$ axioms. (Maddy 1997) provides an argument against $\mathrm{V}=\mathrm{L}$.
} 
Because the currently accepted set-theoretic formalisms cannot express absolute undecidability and hence cannot prove that there is no such rational argument, the absolute undecidability of a proposition cannot be proven. To say that a proposition is absolutely undecidable thus expresses the personal belief that the proposition is beyond our epistemic grasp: our (formal and informal) epistemic capacities are insufficient to assess the truth-value of the proposition.

A central epistemic question of the set-theoretic pluralism debate is about how far our epistemic grasp on set-theoretic propositions reaches: we can prove that there are undecidable statements, but are there absolutely undecidable statements? The arguments that debating set theorists give for their views on the matter tend to rely on heavy mathematical machinery infused with philosophical considerations which are often reliant on metamathematical and philosophical views. ${ }^{28}$ Väänänen calls this the "outside view":

Undecidability of $\varphi$ by given axioms ZFC means the existence of two models $\mathrm{M}_{1}$ and $\mathrm{M}_{2}$ of ZFC, one for $\varphi$ and another for non- $\varphi$. This is indeed the "outside" view about a theory. [... However,] a theory like ZFC is a theory of all mathematics; everything is "inside" and we cannot make sense of the "outside" of the universe inside the theory ZFC itself, except in a metamathematical approach.

The outside view is predominant in the current set-theoretic pluralism debate. Here are three examples.

Hugh Woodin's metamathematical approach is a form of realism:

[Prediction:] There will be no discovery ever of an inconsistency in [the theory "ZFC + 'There exist infinitely many Woodin cardinals"']

One can arguably claim that if this [...] prediction is true, then it is a physical law. (Woodin 2011, p. 449)

Joel D. Hamkins merges Platonism with a philosophical importance of set-theoretic practice:

the continuum hypothesis can no longer be settled in the manner formerly hoped for, namely, by the introduction of a new natural axiom candidate that decides it. Such a dream solution template, I argue, is impossible because of our extensive experience in the $\mathrm{CH}$ and non- $\mathrm{CH}$ worlds.

The multiverse view is one of higher-order realism-Platonism about universes - and I defend it as a realist position asserting actual existence of the

\footnotetext{
28 Peter Koellner's Exploring the Frontiers of Incompleteness project and (Kennedy 2014) contain relevant papers. See (Rittberg 2020) for an analysis of the interplay between philosophy and set-theoretic activity.
} 
alternative set-theoretic universes into which our mathematical tools have allowed us to glimpse. (Hamkins 2012, p. 417)

\section{John Steel is pragmatic:}

In the author's opinion, the key methodological maxim that epistemology can contribute to the search for a stronger foundation for mathematics is: maximize interpretative power. (Steel 2014, p. 154)

Woodin, Hamkins and Steel propose to resolve the issue of absolute undecidability of set-theoretic propositions on the basis of philosophical considerations-what Väänänen calls an "outside view". Väänänen proposes an "inside view" which aims to actively avoid metamathematical and philosophical discourse and instead proposes to engage with absolute undecidability by formal means. Since the currently standard formalisms are incapable of handling absolute undecidability (recall that absolute undecidability of a proposition cannot be expressed by currently standard formalisms), Väänänen proposes to adjust these formalisms. He develops a multiverse logic, which he motivates thus:

we want [multiple] universes in order to account for absolute undecidability and at the same time we want to say that [these] universes are "everything". We solve this problem by thinking of the domain of set theory as a multiverse of parallel universes, and letting variables of set theory range-intuitivelyover each parallel universe simultaneously, as if the multiverse consisted of a Cartesian product ${ }^{[29]}$ of all of its parallel universes. The axioms of the multiverse are just the usual ZFC axioms and everything that we can say about the multiverse is in harmony with the possibility that there is just one universe [until a stronger logic is introduced]. But at the same time the possibility of absolutely undecidable propositions keeps alive the possibility that, in fact, there are several universes. (Väänänen 2014, p. 182)

Väänänen develops his formalism by extending classical logic to so called multiverse logic. He introduces new logical symbols which can express absolute undecidability. At the same time, Väänänen ensures that the new logic does not conflict with the old; the two are "in harmony" as Väänänen says.

Väänänen provides formal means to capture convictions one might have about set-theoretic propositions. For example, using Väänänen's formalism one can formally express the statement "The ZFC axioms are true, $\mathrm{CH}$ is true, and $\mathrm{GCH}$ is absolutely undecidable"- this statement is not expressible by the currently standard formalisms of set theory. Notice that this allows us to express statements formally, it does not force any convictions about the truth of these statements upon us.

\footnotetext{
29 Väänänen adds as a footnote here:’But the Cartesian product is just a mental image. We cannot form the Cartesian product because we cannot even isolate the universes from each other".
} 
Väänänen's formalism is capable of expressing, amongst many other examples, the so-called generic multiverse proposal of Steel as well as that of Woodin, which carries the same name but differs in relevant details. We may read this as evidence for the success of Väänänen's formalism to track the positions currently on offer in the set-theoretic pluralism debate.

\subsection{Discussion}

The provable undecidability of some set-theoretic propositions has put intellectual pressure on the once deeply entrenched dogma that each mathematical proposition is within set theory's epistemic grasp. Today, set theorists debate whether there are limits to this epistemic grasp, whether there are absolutely undecidable statements. Submission to the currently standard formalisms of set-theoretic reasoning cannot answer this question because absolute undecidability is not traceable by the currently standard formalism. And indeed, Väänänen does not submit to these existing reasoning structures. Instead he adapts them to the problem at hand. In this subsection I argue that the accounts of intellectual humility by Whitcomb et al. (owning one's limitations), Roberts and Wood (virtuous disregard for social status), and Kidd (confidence conditions) work well to track Väänänen's manifestations of intellectual humility in his development of multiverse logic.

Recall that Kidd (2016) presented intellectual humility as a two-component virtue. The intellectually humble are (a) disposed to take seriously intellectual pressures on their deeply held beliefs and are (b) willing to revise these beliefs should the pressures demand it. Väänänen (a) takes seriously the current set-theoretic debate about absolute undecidability and (b) develops a formalism capable of expressing limitations in the epistemic grasp on mathematical propositions. That is, Väänänen manifests intellectual humility in his development of multiverse logic according to Kidd's account.

Väänänen introduces his formalism because he wants to avoid an "outside view" in which mathematical discourse is had by philosophical means. Väänänen aims to bring mathematical discourse back into a mathematical realm, an "inside view", i.e. he seeks to engage with the challenges his practice is facing with the means he is arguably an expert in: formal mathematical machinery. There is a recognition of his area of expertise here, which is a sign of intellectual humility on Roberts' and Wood's account. But mere submission to the existing formalisms of set theory cannot handle the issue of absolute undecidability. Väänänen owns this limitation of his intellectual practice in the sense of Whitcomb et al. (2017). He does not seek to provide answers to the issue of absolute undecidability. Instead, he develops a formalism capable of expressing one's view on the issue in mathematically traceable ways. Thus, he recognises his area of expertise here but is simultaneously willing to adapt it to be able to employ it to the issue at hand.

Another dimension on which Väänänen manifests intellectual humility in his work on multiverse set theory is by not forcing any conviction upon us. He provides a formal playing field that is free of assumptions about whether there are any absolutely undecidable statements and which they are should they exist. Väänänen 
provides the formal means to express our convictions that a certain statement is or is not absolutely undecidable. He does not aim to shape our thoughts on this matter; he allows us intellectual freedom. ${ }^{30}$ Thus, Väänänen develops his multiverse logic without the intention to leave his stamp on the mind of his disciples and to shape the field and the views of future generations according to his personal views on absolutely undecidability. In the words of Roberts and Wood (2007), Väänänen does not aim to intellectually dominate his practice. As they have argued, this is a sign of intellectual humility (cf. Sect. 2).

In Sect. 2 I suggested we read Roberts and Wood as a motivational account of intellectual humility: the intellectually humble is not motivated by those external goods of a practice which promise to generate social status. This is the case for Väänänen. Intellectual humility is not a by-product of Väänänen's work. He did not write a paper and intellectual humility manifested by chance. Rather, he is not disposed to dominate his peers by pushing his views on the pluralism debate upon them. His aim in (Väänänen 2014) is to bring a mathematical discourse that is currently had by philosophical means into the realm of mathematically traceable formalisms. There is a sense in which intellectual humility is a driving force for the writing of the paper.

\section{Conclusion}

In this paper I explored how intellectual humility may (fail to) manifest in mathematical practices. I employed virtue-epistemological accounts of this virtue in three case studies of mathematical activity. This showed that recent accounts of intellectual humility are successful at tracking some aspects of intellectual humility in mathematical practices but require adjustments in others. In this section I draw two conclusions from my analysis. First, virtue theorists of mathematics stand to benefit from appropriating accounts of the intellectual virtues provided by the virtue epistemologists. Second, virtue epistemology is enriched through analyses of the virtues in the context of real life practices.

The accounts of intellectual humility provided by virtue epistemology were successful at tracking manifestations of the virtue in the Väänänen-case (Sect. 5), and proved also largely successful for an engagement with the Erdös-Selberg debate (Sect. 3). Virtue epistemology thus has something to offer to virtue theory of mathematics, namely detailed accounts of the intellectual virtues.

On the other hand, what virtue epistemology has to offer is not always successful at tracking the complexities of lived mathematical practices. This was particularly visible in Sect. 4, where I showed that the existing accounts of intellectual humility are insufficient for a virtue-theoretic assessment of the abc-conjecture case.

My suggestion is therefore that virtue theory of mathematics stands to benefit from the intellectual resources provided by virtue epistemology, but these resources

\footnotetext{
30 This freedom is nonetheless limited. Väänänen's multiverse logic cannot express Hamkins' multiverse theory because Hamkins allows for too many (i.e. class many) models of set theory.
} 
may require adjustment to successfully track the virtues as they manifest in mathematics. A suitable term for this is "appropriation". To appropriate intellectual resources, such as accounts of a virtue, means to implement them in one's own intellectual framework, which may require adjustments to the original resource (Schuster 2017; Osler 1997). This paper suggests that virtue theorists of mathematics ought to appropriate the intellectual resources provided by virtue epistemologists.

My second claim in this section is that virtue epistemology is enriched through analyses of the virtues in the context of real life practices. I argue that such analyses can inform us about the nature of the virtues. Additionally, it raises questions about the domain-specificity of the intellectual virtues.

Real-life cases of (failed) manifestations of virtues have characteristically more depth than the pointed thought experiments traditionally relied on in virtue epistemology. For example, my discussion of the abc-conjecture raised the question for Whitcomb et al.'s owning-one's-limitations account of intellectual humility of how much an agent should sacrifice her own intellectual flourishing for the flourishing of her practice. Whitcomb et al. fail to acknowledge this problem, also because they do not consider agents in the context of an intellectual practice. Similarly, the abc-case shows that there can be a remarkable symmetry in intellectual humility: Mochizuki demands from his readers to manifest more humility by getting a better grip on IUT theory, whereas (some of) his readers demand Mochizuki to better own the limitations of his explanation of the results. That conflicting parties can accuse each other of not being sufficiently humble in their epistemic endeavours is a facet of intellectual humility which has remained unstudied by contemporary virtue epistemology.

Arguably, these insights could have also been obtained from sufficiently smartly constructed thought experiments. The point is, however, that they did not. Thought experiments of the kinds employed in contemporary virtue epistemology are helpful at highlighting issues, but they are bound to oversimplify and thereby overlook facets of the virtue under study that reveal themselves naturally when considering real-life cases.

Studying real-life cases of manifestations of the intellectual virtues can furthermore inform debates in virtue epistemology. Recall that Whitcomb et al. criticised Roberts' and Wood's virtuous-inattentiveness-to-social-status account of intellectual humility by pointing out that one can be intellectually humble and pay attention to one's social status (Sect. 3). My study of the Erdős-Selberg dispute both supported Whitcomb et al.'s criticism and suggested a refinement of Roberts' and Wood's to a motivational account. This theme was taken up again in Sect. 4, where I pointed out that if the intellectually humble were inattentive to social status, they would make bad reviewers for mathematical papers.

In Sect. 2 I remarked that the ahistorical conceptual analysis of the virtues offered by much of contemporary virtue epistemology suggests that intellectual humility is much the same across all epistemic endeavours. In their contribution to this Topical Collection, Tanswell and Kidd (2020) question this suggestion. They offer a tripartite distinction: (a) generic virtues, which are pertinent to all types of enquiry in a domain neutral way; (b) specific epistemic virtues, which are generic virtues that take domain-specific forms; (c) local virtues, which are pertinent to a certain subject. In this paper I have argued that intellectual humility manifests differently in 
mathematical practices than it does in the conceptual analysis provided by the virtue epistemologists. This aligns with Tanswell's and Kidd's insights. However, to claim that intellectual humility manifests differently in mathematical practices than elsewhere implies that mathematical practices are different from other epistemic practices. To argue for such a claim would require a comparative study, which is well beyond the scope of this paper. Suffice to say here that my engagement with mathematical practices focussed on disputes about intellectual ownership, correctness of results, and adaptations of deeply held beliefs, all of which feature in epistemic practices other than mathematics as well. Whether or not the disputes and adaptations discussed in this paper were informed by any specifically mathematical features that such disputes would lack in other epistemic practices would require further study. This paper thus remains inconclusive on the question whether there are specifically mathematical intellectual virtues. ${ }^{31}$

Virtue epistemology offers valuable theoretical reflections and the philosophy of mathematical practices can provide access to a host of real-life case studies. The development of a virtue theory of mathematical practices thus promises to be beneficial to both intellectual projects.

Acknowledgements I wish to thank Juliette Kennedy for inspiring my work on intellectual humility in mathematics, Jouko Väänänen for lengthy personal discussions about his views on set theory, and Andrew Aberdein, Joachim Frans, Brendan Larvor, Andrew Morris, Pieter Present, Aleksandra Samonek, Alessandra Tanessini, Fenner Stanley Tanswell, Jean Paul Van Bendegem, Jip Van Besouw, and two anonymous reviewers for helpful comments and criticisms. Early drafts were presented at the SPSP2018, the Novembertagnug 2018, and at a research seminar of the Center for Logic and Philosophy of Science at the Vrije Universiteit Brussel, and I am grateful for the engaging discussions with the audiences. Research for this paper has been funded by the Research Foundation-Flanders (FWO), project G056716N, the Centre for Mathematical Cognition at Loughborough University, and the European Commission via the Marie Skłodowska-Curie Individual Fellowship scheme (Grant Agreement ID: 883724).

Open Access This article is licensed under a Creative Commons Attribution 4.0 International License, which permits use, sharing, adaptation, distribution and reproduction in any medium or format, as long as you give appropriate credit to the original author(s) and the source, provide a link to the Creative Commons licence, and indicate if changes were made. The images or other third party material in this article are included in the article's Creative Commons licence, unless indicated otherwise in a credit line to the material. If material is not included in the article's Creative Commons licence and your intended use is not permitted by statutory regulation or exceeds the permitted use, you will need to obtain permission directly from the copyright holder. To view a copy of this licence, visit http://creativecommons.org/licen ses/by/4.0/.

\section{References}

Aberdein, A., Rittberg, C. J., \& Tanswell, F. S. (2020). Virtue Theory of Mathematical Practices. Topical Collection of Synthese.

Antos, C., Friedman, S. D., Honzik, R., \& Ternullo, C. (2015). Multiverse conceptions in set theory. Synthese, 192(8), 2463-2488.

$\overline{31}$ For an insightful study of rigour as an intellectual virtue of mathematics, see (Tanswell 2016). 
Baas, N., \& Skau, C. (2008). The lord of the numbers, AtleSelberg. On his life and mathematics. Bulletin of the American Mathematical Society, 45(4), 617-649.

Ben-Ze'ev, A. (1993). The virtue of modesty. American Philosophical Quarterly, 30(3), 235-246.

Bloor, D. (1976). Knowledge and social imagery (2nd ed.). Chicago: University of Chicago Press.

Brown, L. (2009). Aristotle, the Nicomachean ethics. Oxford: Oxford World's Classics Oxford University Press.

Button, M. (2005). A Monkish Kind of Virtue? For and Against Humility. Political Theory, 33(6), $840-868$.

Calegari, F. (2017). The abc conjecture has (still) not been proved. https://www.galoisrepresentation s.com/2017/12/17/the-abc-conjecture-hasstill-not-been-proved/.

Castelvecchi, D. (2020). Mathematical proof that rocked number theory will be published. Nature, 580, 177.

Centrone, S., Kant, D., \& Sarikaya, D. (2019). Reflections on the foundations of mathematics. Switzerland: Springer.

Coates, J. (1984). The work of Gross and Zagier on Heegner points and the derivatives of L-series. Séminare Bourbaki 37e année, 1984-85, $n^{\circ}, 635,57-72$.

Conrad, B. (2015). Notes on the Oxford IUT workshop. Retrieved 15 January 2021. https://mathbabe. org/2015/12/15/notes-on-the-oxford-iut-workshop-by-brian-conrad/.

Crowell, R. (2017). On a summary of Shinichi Mochizuki's proof for the abc conjecture. American Mathematical Society. http://www.ams.org/news?news_id=3711.

de Montaigne, M. (2015). Essays of Montaigne. Irvine: Xist Publishing.

Driver, J. (1989). The virtues of ignorance. The Journal of Philosophy, 86(7), 373-384.

Dutilh Novaes, C. (2016). Reductio ad absurdum from a dialogical perspective. Philosophical Studies, $173,2605-2628$.

DutilhNovaes, C. (2020). The philosophy of deduction. Cambridge: Cambridge University Press.

Elkies, N. D. (2007). The ABC's of number theory. The Harvard College Mathematics Review, 1(1), 57-76.

Farmelo, G. (2009). The strangest man: The hidden life of Paul Dirac. London: Faber \& Faber.

Gödel, K. (1947). What is Cantor's Continuum Problem. Reprinted. In F. Solomon, (ed.), Kurt Gödel, Collected Works II. 1990 (pp. 176-187) Oxford University Press.

Goldfeld, D. (2004). The elementary proof of the prime number theorem: An historical perspective. Number Theory (pp. 179-192). New York: Springer.

Hamkins, J. D. (2012). The set-theoretic multiverse. The Review of Symbolic Logic, 5(3), 416-449.

Hazlett, A. (2012). Higher-order epistemic attitudes and intellectual humility. Episteme, 9(3), 205-223.

Hoffman, P. (1998). The man who loved only numbers. New York: Fourth Estate.

Hume, D. (1740). A Treatise in Human Nature. 2009 reprint: The Floating Press.

Kennedy, J. (Ed.). (2014). Interpreting Gödel: Critical essays. Cambridge: Cambridge University Press.

Kidd, I. J. (2016). Intellectual humility, confidence, and argumentation. Topoi, 35(2), 395-402.

Kidd, I. J., 2017. Confidence, Humility, and Hubris in Victorian Scientific Naturalism. In (van Dongen and Paul 2017).

Kidd, I. J., Medina, J., \& Pohlhaus, G. (2017). The Routledge handbook of Epistemic injustice. Abingdon: Routledge.

Klarreich, E. (2018). Titans clash over epic proof of abc conjecture. Quanta Magazine. https://www.quant amagazine.org/titans-of-mathematicsclash-over-epic-proof-of-abc-conjecture-20180920/\#.

Konkola, K. (2005). Have we lost humility? Humanitas, 18(1-2), 182-207.

MacIntryre, A. (1981). After virtue. Bristol: Bristol Classical Press.

Maddy, P. (1997). Realism in mathematics. Oxford: Oxford University Press.

Maddy, P. (2011). Defending the axioms. Cambridge: Cambridge University Press.

Maddy, P. (2017). Set-theoretic Foundations. In A. E. Caicedo, J. Cummings, P. Koellner, \& P. B. Larson (Eds.), Foundations of mathematics (Vol. 690). Providence: American Mathematical Society.

Maddy, P. (2019). Reply to Ternullo on the Multiverse. In (Centrone et al. 2019). 69-78.

Mochizuki, S. (2019). Report on discussions held during the period March 15-20, 2018, concerning inter universal Teichmüller theory (IUTCH). http://www.kurims.kyoto-u.ac.jp/ motizuki/Rpt2018.pdf.

Nietzsche, F. (1989). Beyond Good and Evil: Prelude to a Philosophy of the Future, trans (p. 1966). Walter Kaufmann (New York: Vintage.

Nuyen, A. T. (1998). Just modesty. American Philosophical Quarterly, 35, 101-109.

Osler, M. (1997). Mixing Metaphors: Science and religion or natural philosophy and theology in early modern Europe. History of science, 36(1), 91-113. 
Rittberg, C. J. (2020). Mathematical practices can be metaphysically laden. In S. Bharath (Ed.), Handbook of the history and philosophy of mathematical practices. Cham: Springer. https://doi. org/10.1007/978-3-030-19071-2_22-1.

Rittberg, C. J. (2016). Methods, goals, and metaphysics in contemporary set theory. Ph.D. Thesis. Retrieved 15 January 2021 from https://uhra.herts.ac.uk/handle/2299/17218.

Roberts, D. M. (2019). A crisis of identification. Inference, International Review of Science. https://infer encereview.com/article/a-crisis-of-identification.

Roberts, R. C., \& Wood, W. J. (2007). Intellectual virtues: An essay in regulative epistemology. New York: Oxford University Press.

Rushing, S. (2013). Comparative humilities: Christian, contemporary, and Confucian conceptions of a political virtue. Polity, 45(2), 198-222.

Sachs, J. (2002). Aristotle Nicomachean Ethics. Bemidji: Focus Publishing.

Scholze, P., \& Stix, J. (2018). Why abc is still a conjecture. https://pdfs.semanticscholar.org/0253/b621d 24779fad66e6c24312138bcc509f9da.pdf.

Schuster, J. (2017). Consuming and appropriating practical mathematics and the mixed mathematical fields, or being "influenced" by them: The case of the young descartes. In L. Cormack, S. Walton, \& J. Schuster (Eds.), Mathematical practitioners and the transformation of natural knowledge in early modern Europe (pp. 37-65). Cham: Springer.

Selberg, A., \& Devine, B. (1989). Oral history interview of Atle Selberg. Retrieved 15 January 2021 from https://albert.ias.edu/bitstream/handle/20.500.12111/1037/Selberg_OH_1989_final.pdf.

Spencer, J., \& Graham, R. (2009). The elementary proof of the prime number theorem. The Mathematical Intelligencer, 31(3), 18-23.

Spiegel, J. S. (2012). Open-mindedness and intellectual humility. Theory and Research in Education, $10(1), 27-38$

Spinoza, B. (1994). The Ethics and other works, edited and translated by Edwin Curley. Princeton: Princeton University Press.

Steel, J. (2014). Gödel’s program. In J. Kennedy (Ed.), Interpreting Gödel (pp. 153-179). Cambridge: Cambridge University Press.

Tanesini, A. (2018). Intellectual humility as attitude. Philosophy and Phenomenological Research, 96(2), 399-420.

Tanswell, F. S. (2016). Proof, Rigour \& Informality: A Virtue Account of Mathematical Knowledge, St Andrews, University of St Andrews, PhD Thesis.

Tanswell, F. S., \& Kidd, I. J. (2020). Mathematical Practice and Epistemic Virtue and Vice. In: (Aberdein et al. 2020).

Ternullo, C. (2019). Maddy on the multiverse. In: (Centrone et al. 2019). 43-78.

Väänänen, J. (2014). Multiverse set theory and absolutely undecidable propositions. In J. Kennedy (Ed.), Interpreting Gödel (pp. 180-208). Cambridge: Cambridge University Press.

van Dongen, J., \& Paul, H. (2017). Epistemic Virtues in the Sciences and the Humanities. Cham: Springer.

van der Poorten, A. J. (1996). Notes on Fermat's Last Theorem. Canadian Mathematical Society Series of Monographs and Advanced Texts.

Whitcomb, D., Battaly, H., Baehr, J., \& Howard-Snyder, D. (2017). Intellectual humility: Owning our limitations. Philosophy and Phenomenological Research, 94(3), 509-539.

Woodin, W. H. (2011). The transfinite universe. In M. Baaz, C. H. Papadimitriou, H. W. Putnam, D. S. Scott, \& C. L. Harper Jr. (Eds.), Kurt Gödel and the foundations of mathematics: Horizons of truth. Cambridge: Cambridge University Press.

Yamashita, G. (2017). A proof of the abc conjecture after Mochizuki. Preprint available at http://www. kurims.kyoto-u.ac.jp/ gokun/myworks.html.

Publisher's Note Springer Nature remains neutral with regard to jurisdictional claims in published maps and institutional affiliations. 